\title{
Movimento de favelas de Belo Horizonte e os católicos conservadores"
}

\section{Social movements in the favelas in the city of Belo Horizonte and the conservative catholics}

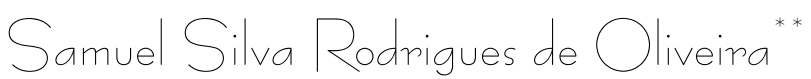

\section{Introdução}

No dia 1 de abril de 1964, Isabel de Basto, moradora da favela Cabana do Pai Tomás, registrou em seu diário:

Graças a meu Deus!

A vitória está se aproximando!

Minha luta em defesa da nossa religião, em defesa da própria Democracia!

Em defesa dos inocentes!

Pela paz dos nossos povos! Pela vitória das nossas famílias. Estou tão comovida que nem sei a quem posso dirigir tão humildes palavras!

Viva as Forças Armadas! ${ }^{11}$

\footnotetext{
* O artigo apresentado é a reformulação de parte da dissertação defendida no programa de pós-gradução em História e Culturas Políticas da Universidade Federal de Minas Gerais (UFMG), orientada pelo Prof. Dr. Rodrigo Patto Sá Motta.

** Doutorando em Bens Culturais, História e Política, pelo programa de PósGraduação do CPDOC/FGV, bolsista de doutorado da Fundação de Amparo à Pesquisa do Estado do Rio de Janeiro (FAPERJ), orientado pela Prof ${ }^{a}$. Dr ${ }^{a}$. Dulce Chaves Pandolfi.

${ }^{1}$ [Diário de Isabel Bastos, 1964] Arquivo Publico Mineiro. Fundo DOPS. Pasta 0121. 
Esse diário, produzido entre o final de 1963 e princípio de 1964, testemunhava a legitimidade do Golpe de 1964 entre alguns grupos católicos que moravam em favelas. Quando observa-se a finalidade do diário, pode-se deduzir a participação ativa no processo de repressão a segmentos da esquerda que atuavam nas favelas e a coloboração com a polícia política. $\mathrm{O}$ diário foi produzido para ser entregue ao Departamento de Ordem Politica e Social (DOPS), como meio de combater a Liga Feminina e Raimundo Gil, membro do Partido Comunista Brasileiro (PCB) e líder da associação de favelas da Cabana do Pai Tomás.

A participação e legitimidade popular na repressão desencadeada pelo Golpe de 1964 têm sido avaliadas de forma bastante parcial: o amplo escopo de classes e grupos que foram politicamente ativos no Golpe são esquecidos ou tratados de forma esquemática. As Ciências Humanas têm demonstrado maior interesse em pesquisar os "revolucionários" e a "esquerda" em detrimento das forças ligadas à "defesa da ordem". ${ }^{2}$ As ações e práticas dos grupos de direta têm permanecido como um ângulo morto da análise social : reconhece-se sua impotância, mas continua sendo pouco explorado.

Na historiografia, o trabalho de Armand René Dreifuss é um marco para a reflexão. O conceito de "golpe civil-militar" apontou justamente para a participação de civis no golpe, para além dos militares. Contudo, enfatizou a relação entre as elites econômicas e o comportamento político de direita. Os movimentos que atingiram repercussão entre vários segmentos sociais foram analisados em relação à ação de cooptação da burguesia industrial e das classes médias. Ao frisar o caráter conspiratório do golpe movido por uma elite civil-militar, o clássico 1964: A Conquista do Estado não aprofundou a análise das iniciativas de populares que apoiaram o Golpe. Abordar essa questão enfraqueceria o argumento central do autor: o Golpe de 1964 foi arquitetado pela burguesia "multinacional-associada" contra o bloco "nacional-popular". ${ }^{3}$ Todavia, como

\footnotetext{
${ }^{2}$ MOTTA, R. P. S. Em guarda contra o Perigo Vermelho: o anticomunismo no Brasil (1917-1964). São Paulo: Perspectiva, 2001. p. XXII.

${ }^{3}$ DREIFUSS, R. A. 1964: a conquista do Estado - Ação política, poder e golpe de classe. 3. ed. Petrópolis: Vozes, 1981.
} 
explicar reações como a de Isabel Bastos e outras organizações politicas de direita nas favelas de Belo Horizonte? Estariam elas vinculadas à burguesia multinacional-associada?

A relação entre estrutura socioeconômica e comportamento político de direita tem sido revista por autores que valorizam a reflexão sobre as identidades, que se preocupam em explicar como as "representações do mundo social" legitimam e orientam práticas sociais. A historiografia renovada pela reflexão sobre a cultura tem sido atenta ao modo como os grupos e indivíduos constroem uma autoimagem em relação à alteridade, numa tensão constante com as práticas sociais. ${ }^{4}$ Em oposição à hipótese de que os moradores pactuavam com o "bloco multinacional-associado", este trabalho compreende que as práticas politicas dos moradores inseriam-se num conjunto de relações constitutivas do movimento de favelas e na forte polarização politica entre direita e esquerda no início da década de 1960.

Em 1961, com a posse de João Goulart, viu-se a renovação de um imaginário anticomunista com fortes raízes na sociedade brasileira. Durante o século XX, a Revolução Russa (1917) e o comunismo constituíram uma das orientações para a transformação do Estado e da sociedade, sendo o horizonte de ação para vários "revolucionários". O Partido Comunista do Brasil (PCB) foi fundado em 1922 e, à medida que sua militância ganhou importância, aumentava também o anticomunismo como estratégia para defesa da ordem e para barrar iniciativas de transformação da ordem social. Segundo Sá Motta, em momentos-chave da história republicana brasileira, o anticomunismo formou uma "sagrada aliança" entre católicos,

\footnotetext{
${ }^{4}$ Para uma discussão sobre a renovação provocada pela noção de cultura na historiografia cf.: CHARTIER, R. História Intelectual e história das mentalidades: uma dupla reavaliação. In: A História Cultural: entre práticas e representações. Lisboa: Difel, 1990. p. 29-67; CHARTIER, R. "O mundo como representação", Revista Estudos Avançados, v. 5, n.11, São Paulo, 1991. p. 173-191; RICOUEUR, P. Explicação/Compreensão. In: A memória, a história, o esquecimento. Campinas: Ed. Unicamp, 2007. p. 193-245; HUNT, L. Apresentação: história, cultura e texto. In: A Nova História Cultural. 2. ed. São Paulo: Martins Fontes, 2006. p. 1-29; CEFAÏ, D. Introduction. In: Cultures Politiques. Paris: Press Universitaires de France, 2001. p. 5-31; GEERTZ, C. A ideologia como sistema cultural. In: A interpretação das culturas. Rio de Janeiro: LTC, 1989. p. 107-134.
} 
liberais e militares para defesa da ordem, articulando golpes e instituindo ditaduras. No contexto de Guerra Fria, no embate entre União Soviética e Estados Unidos, a cultura anticomunista serviu de esteio para o Golpe de 1964 e para a formação de uma aliança entre os grupos que possuiam projetos políticos distintos, mas identificavam um inimigo em comum - o comunismo expresso na Revolução Cubana (1959) e as forças politicas de esquerda que ascenderam ao poder juntamente com João Goulart. ${ }^{5}$

Os estratos sociais mais pobres não ficaram alheios a essa movimentação: a cultura anticomunista também interpelou alguns moradores de favelas na defesa da ordem. Eles se chocaram com a direção esquerdista do associativismo organizado pela Federação dos Trabalhadores Favelados de Belo Horizonte (FTFBH), construindo outra identidade para o movimento de favelas. Neste artigo, analisam-se dois grupos católicos conservadores ${ }^{6}$ que se mobilizaram na defesa da ordem contra a direção esquerdista da FTFBH: a formação da dissidência, através da Organização Social dos Trabalhadores Favelados, e da oposição liderada por Isabel Bastos na Vila Operário-Estudantil.

Para realizar a oposição à esquerda política, essas associações civis em favelas vão realizar um trabalho de representação do mundo: classificavam a realidade e apontavam contradições e descontentamentos em relação às práticas politicas do associativismo coordenado pela FTFBH. Segundo Roger Chartier, as representações do mundo constituem "formas institucionalizadas e objetivadas graças às quais uns 'representantes' (instâncias coletivas ou pessoas singulares) marcam de forma visivel e perpetuada a existência do grupo,

\footnotetext{
${ }^{5}$ Para compreensão do anticomunismo no Brasil como elemento constitutivo da direita no Brasil e de sua importância como elemento explicativo da mobilização golpista em 1964 cf.: MOTTA, R. P. S. Em guarda contra o Perigo Vermelho: o anticomunismo no Brasil (1917-1964). São Paulo: Perspectiva, 2001; MOTTA, R. P. S. João Goulart e a mobilização anticomunista de 1961-1964. In: FERREIRA, M. M. (Org.). João Goulart: entre a memória e a História. Rio de Janeiro: ed. FGV, 2006. p. 129-149.

${ }^{6}$ A noção de conservadorismo católico utilizada nesse trabalho será explicada mais abaixo quando abordaremos a relação entre movimento de favelas e a cultura católica.
} 
classe ou comunidade". ${ }^{7}$ Ao organizarem e apresentarem publicamente sua representação do mundo, esses grupos faziam reconhecer uma identidade social, exibiam uma maneira própria de estar no mundo e significavam simbolicamente um estatuto e uma posição em relação à luta das favelas.

Além de contribuir para uma percepção da atuação da direita no movimento social de favelas, este artigo também é uma contribuição à história ao estudo das favelas no Brasil. Na "bibliografia analitica" sobre as favelas, Lícia Prado Valladares e Lídia Medeiros salientaram que apenas 3\% do conjunto dos 668 títulos levantados pertenciam à disciplina "História". A contribuição mais evidente era proveniente da sociologia urbana (19\%), planejamento urbano/arquitetura (18\%), antropologia urbana (14\%) e as produções institucionais do poder público $(9 \%) .{ }^{8}$ A pouca importância da produção historiográfica nessa produção contribuiu para que as dimensões temporais do fenômeno "favela" fossem pouco problematizadas. Os analistas ficavam presos aos elementos sincrônicos do sistema social, perdendo a diacronia - a inserção do objeto de estudo na duração dos tempos históricos.

Assim, o texto articula aos estudos sobre favela uma dimensão muito particular do tempo político brasileiro: a participação dos grupos populares na República brasileira. Como enfatizou José Murilo de Carvalho, diferente de outros países em que o ideal e as práticas republicanas vieram acompanhados de uma ampliação do poder do povo, no Brasil o povo assistiu "bestializado" o nascimento da República, foi excluído do jogo político formal. ${ }^{9}$ A história republicana brasileira do longo século XX pode ser compreendida através da luta para a ampliação da participação.

\footnotetext{
7 CHARTIER, R. História Intelectual e história das mentalidades: uma dupla reavaliação. In: A História Cultural: entre práticas e representações. Lisboa: Difel, 1990. pp.23.

${ }^{8}$ VALLADARES, L. do P. \& MEDEIROS, L.. Pensando as favelas do Rio de Janeiro (1906-2000) - Uma bibliografia analítica. Rio de janeiro: Relume Dumará/FAPERJ, 2003. p. 17; VALLADARES, L. do P. A invenção da favela: do mito de origem a favela.com. Rio de Janeiro: FGV, 2005. p. 144.

${ }^{9}$ CARVALHO, J. M.. Os bestializados: Rio de Janeiro e a República que não foi. São Paulo: Cia das Letras, 1987.
} 
Um dos caminhos de afirmação dessa participação foi a positivação da categoria "favelado" como identidade para formação de associações civis diversas. A mobilização dos moradores de favelas foi um indício da maneira como um estigma imputado à pobreza urbana foi transformando em categoria de luta para a ampliação da cidadania no Brasil entre 1945 e 1964. ${ }^{10}$

\section{A formação do movimento de favelas de Belo Horizonte}

O movimento de favelas de Belo Horizonte nasceu como fruto da mudança do contexto sociopolítico da cidade em meados do século XX. Em 1947, a capital mineira passou a ter instituições características da democracia: uma câmara municipal e um executivo eleito pelo voto popular. Desde sua fundação (1897), a cidade era administrada por um prefeito e pelo conselho deliberativo escolhidos pelo governador do estado de Minas Gerais; agora, os moradores escolhiam representantes municipais. ${ }^{11}$ Essa situação, somada à conjuntura nacional de instituição de uma democracia liberal, com o retorno dos direitos políticos após o fim do Estado Novo, colaborou para o aumento da participação popular. ${ }^{12}$

A luta pelo direito de moradia, pela regularização da posse dos terrenos e pela conquista de melhorias urbanas surgiu nesse cenário. A Associação de Defesa Coletiva da Vila São Vicente de Paulo (ou "Vila dos Marmiteiros") nasceu em 1948, no momento de abertura à participação política no governo da cidade e em vista das ameaças de despejo que os moradores estavam sofrendo. A luta da Vila São Vicente de

\footnotetext{
${ }^{10}$ BURGOS, M. Dos Parques Proletários ao Favela-Bairro. In: ZALUAR, A., ALVITO, M. (Org.). Um século de Favela. 5. ed. Rio de janeiro: Ed. FGV, 2006. p. 27.

${ }^{11}$ SILVA, R. H. A. da. O legislativo e a cidade: domínios de construção do espaço público. Belo Horizonte: Câmara Municipal, 1998. p. 49

12 SOMARRIBA, M. das M. G.; VALADARES, M. G. \& AFONSO, M. R.. Lutas urbanas em Belo Horizonte. Petrópolis: Vozes, 1984. p. 30-44; CARVALHO, J. M. de. Cidadania no Brasil: o longo caminho. Rio de Janeiro: Civilização Brasileira, 2001. p. 126-144.
} 
Paulo repercutiu para outras vilas e o modelo do associativismo inventado ganhou outros adeptos na década de 1950, como, por exemplo, na Vila São José (ou Morro do Querosene), com a fundação de outro "Comitê de Defesa Coletiva". ${ }^{13}$

Colaborou para a expansão do associativismo a alteração da relação entre as favelas e a municipalidade na administração de Celso Melo de Azevedo. O prefeito udenista, identificado com a "democracia cristã", governou a cidade entre 1955 e 1958, dando tratamento especial às demandas populares. $\mathrm{O}$ atendimento das associações de favelas foi priorizado com a fundação do Departamento de Bairros Populares, ${ }^{14}$ criado com o apoio do vereador Leopoldo Garcia Brandão, conhecido por defender os interesses da Associação de Defesa Coletiva da Vila São Vicente de Paulo. ${ }^{15}$

Todavia, a difusão do associativismo de defesa coletiva em larga escala só viria a acontecer no início da década de 1960. Com Amintas de Barros na prefeitura (1959-1963), as conquistas advindas com a administração de Celso Melo Azevedo ficaram ameaçadas, estimulando a reunião das associações de favelas para formarem a Federação dos Trabalhadores Favelados de Belo Horizonte (FTFBH). Sob incentivo da FTFBH, entre 1959 e 1964, o número de associações de favelas estendeu-se de nove para 55 (Ver Tabela 1). As entidades tinham nomes variados, mas seguiam o modelo associativo da Vila São Vicente; publicamente, muitas se reconheciam pela sigla "UDC" (União de Defesa Coletiva). ${ }^{16}$

${ }^{13}$ GONÇALVES, V. Belo Horizonte, Brasil, 28 jan. 2008, Arquivo WAVE (148 min.). Entrevista concedida ao pesquisador; BRAGA, W. da S., WATANABE, H. Morro do Querosene - alguns aspectos da formação de uma favela. Belo Horizonte: Diretório Acadêmico da Faculdade de Filosofia da Universidade de Minas Gerais, 1961. p. 28-33.

14 BELO HORIZONTE. Departamento de Bairros Populares. Belo Horizonte: Imprensa Oficial, 1956.

15 [Depoimento de Padre Francisco Lage Pessoa, 27 abr. 1964] Arquivo Público Mineiro. Fundo DOPS. Pasta 0173.

${ }^{16}$ Se lermos o primeiro exemplar do jornal O Barraco, o "órgão oficial da Federação dos Trabalhadores Favelados", vamos encontrar no logotipo do periódico a inicial "UDC" gravada em uma casa humilde, que representava a sede de uma associação de favela. Cf.: [O Barraco, jan.1962] Arquivo Público Mineiro. Fundo DOPS. Pasta 0119. 
Tabela 1 - O crescimento do número de UDCs ligadas a FTFBH

\begin{tabular}{cc}
\hline Ano & $\mathbf{N}^{\mathbf{0}}$ de associações \\
\hline 1959 & 9 \\
1960 & - \\
1961 & 27 \\
$1962\left(^{*}\right)$ & $31 / 41$ \\
1963 & - \\
1964 & 55 \\
\hline
\end{tabular}

Fonte: As informações sobre o número de associações encontram-se dispersas em várias fontes. Cf. Binômio, Belo Horizonte, 20 ago.1962, Caderno 3, p. 3; Última Hora - edição de Minas, Belo Horizonte, 17 nov.1961, p. 2; Diário da Tarde, Belo Horizonte, 11 jan. 1962, p. 5; [Ata da Assembléia Geral dos Moradores da Vila Carlos Josafat, 19 jan. 1964] Arquivo Público Mineiro. Fundo DOPS. Pasta 0121; SOMARRIBA, M. das M. G.; VALADARES, M. G. \& AFONSO, M. R. Lutas urbanas em Belo Horizonte. Petrópolis: Vozes, 1984. p. 42.

Nota: (*) Número referente ao primeiro e segundo semestre de 1962.

A história da formação do movimento de favelas manteve estreita relação com a maneira de ocupação do solo e de distribuição dos equipamentos urbanos na cidade. O crescimento urbano nas décadas de 1950 e 1960 marcou-se pelo aumento do número de moradores em favelas; a quantidade de habitantes em favelas entre 1955 e 1966 saltou da ordem de 36.432 para $119.799 .{ }^{17} \mathrm{O}$ aumento era fruto da ocupação de lotes pertencentes ao poder público, ou de particulares, sem infraestrutura sanitária ou arruamento, próximos às principais vias de transporte da cidade. Segundo o levantamento do IBGE em 1955, dos 6.806 barracões identificados, apenas em 540 casos o morador era dono do terreno. ${ }^{18}$ A grande maioria dos moradores via seu direito de moradia constantemente ameaçado por tentativas de despejo.

\footnotetext{
${ }_{17}$ MINAS GERAIS. Levantamento da População Favelada de Belo Horizonte. Belo Horizonte: Imprensa Oficial, 1966. p.18.

18 BELO HORIZONTE. Departamento de Bairros Populares. Belo Horizonte: Imprensa Oficial, 1956. p. 8
} 
Disputas e conflitos sobre a ocupação dos terrenos urbanos marcaram o cotidiano dos moradores da cidade, como ficou evidenciado na reclamação publicada na seção de jornal intitulada "Alô, alô": ${ }^{19}$

\section{Invasão}

- Alô!

- Pronto.

- Fala um morador da Vila Paraíso, que dá um grito de alerta aos proprietários dos terrenos da Rua Joaquim Ramos. Suas terras estão sendo invadidas por favelados. Estão surgindo barracões em quantidade da noite para o dia. Corram depressa! Cerquem os seus lotes comprados à custa de muito sacrificio e que agora são invadidos! Aqui fica o meu grito de alerta. O sr. Publica?

- Vamos publicar, sim.

- Muito obrigado.

- Não há de que. ${ }^{20}$

O movimento social cresceu como uma resposta dos moradores de favelas para garantir o seu "direito de morar" e contra o crescimento urbano elitista. Mobilizavam-se contra a prática estabelecida, desde o início do século XX, de expulsar a pobreza para áreas distantes dos centros providos de infraestrutura, tendo em vista a valorização das áreas de ocupação regular. Reclamavam pela segurança de sua moradia e para instalação de equipamentos urbanos em favelas.

\section{Movimento de favelas e cultura católica}

No processo de mobilização pelo direito a moradia houve um processo de apropriação do catolicismo e reinvenção as formas de vivenciar a religião e a politica. O trecho do discurso de Padre Lage permite vislumbrar essa relação presente na fundação da primeira UDC:

\footnotetext{
${ }^{19}$ A coluna "Alô, alô!" era publicada no jornal Diário da Tarde e retratava o cotidiano da cidade através de reclamações recebidas pelo telefone e pelo programa Belo Horizonte em Revista, da Rádio Guarani.
}

${ }^{20}$ Diário da Tarde, Belo Horizonte, 2 ago.1962, p. 8. 
Belo Horizonte tomou conhecimento de nossa existência e de nossa esperança [na Vila São Vicente]. Compramos um barracão ao lado da igrejinha, destinando dois cômodos - o sagrado e o profano - a uma escolinha, que era preciso fundar.

Tempo memorável foi aquele, na história do povo. Pouco importa que hoje não exista mais a Vila São Vicente ou dos Marmiteiros, cuja desapropriação deu lugar a uma bela avenida da parte moderna de Belo Horizonte. Provou-se à sociedade [sic] a capacidade de organização dos favelados brasileiros, na Associação de Defesa Coletiva, que funcionou em regime de sessão permanente, todos os domingos, desde as três horas da tarde até ao anoitecer. Nos longos debates acerca dos vários acontecimentos da semana, debates de igreja cheia de homens e mulheres, inteiramente participantes, foram-se criando pouco a pouco a consciência da luta pelo direito de morar, cimentada pela verificação de que a união de todos conseguia o que antes parecia um sonho. ${ }^{21}$

O trecho é significativo por apresentar a mistura entre religião e política na fundação da primeira UDC e na organização das práticas associativas. Padre Francisco Lage Pessoa, ao longo do trecho em que narrou sua chegada a Belo Horizonte, enfatizou sua procura por estabelecer contato com a "população pobre", "subindo as favelas". Essa aproximação inseria-se no quadro da luta travada pelos católicos contra o "ateísmo" e o "comunismo" nas classes populares - segundo Padre Lage, essa foi a "pedra angular do pontificado de Pio XII". ${ }^{22}$.

A fundação da primeira UDC apareceu como fruto desse contato e do novo sentido da "fé cristã" consubstanciada na prática associativa e no engajamento da luta por moradia. Outros padres, como Agnaldo Leal e Tarcísio Rocha, emprestaram prestígio e apoio ao novo associativismo na década de 1950. Esse diálogo consagrou-se na publicação do manifesto dos párocos belohorizontinos pelo "direito de morar" em 1959, apoiando a luta das favelas. ${ }^{23}$

Padres e leigos ajudavam a criar associações de favelas e estavam atrelados a uma Igreja que procurava reestruturar

${ }^{21}$ LAGE, P. O padre do Diabo. São Paulo: BMW, 1988. p. 72-74.

${ }^{22}$ Ibidem, p. 74-45.

${ }^{23}$ Binômio, Belo Horizonte, 22 jun.1959, Caderno 2, p. 5. 
seu corporativismo e sua inserção no mundo, desvencilhando-se do rótulo que a vinculava a "regimes totalitários". Reformulando a imagem do corpo social harmônico que orientou a doutrina social católica, o papado de Pio XII (1939-1958) retomava a noção de "comunidade autônoma" opondo-a tanto ao individualismo liberal quanto ao materialismo socialista. Segundo Roberto Romano:

Respondendo ao fracasso do corporativismo teocrático e ao desastre da colaboração com o totalitarismo, rejeitando penosamente a aproximação entre doutrina social católica e as ditaduras de Vichy e as de pós-guerra (Salazar e Franco, com particularidade), a Igreja mudará gradativamente a terminologia com que, até Pio XI, expunha seu programa de ação junto à base social capitalista. As "corporações" foram rebatizadas, recebendo o nome de "comunidades menores" (societatis minores) que deveriam ser "não impostas autoritariamente pelo Estado, mas autônomas". ${ }^{24}$

A noção de comunidade articulou-se à luta pela difusão da fé, pela conquista da justiça social e por ampliação da participação popular, ganhando contornos que marcariam uma aproximação da Igreja com os leigos. A história do associativismo de favelas em Belo Horizonte nas décadas de 1950 e 1960 adquiriu uma ambiguidade pelas leituras distintas dessa noção de comunidade: ela tanto serviu para organizar a luta politica para conservar tradições cristãs e um regime político "anticomunista", como abriu o diálogo com outras frentes politicas, contestando as estruturas sociais tendo em vista a "reforma" ou "revolução" do Estado.

O embate de práticas e representações "progressistas" e "conservadoras" foi constitutivo da história do catolicismo e dos modelos de cristandade após a Segunda Guerra Mundial. ${ }^{25}$ Segundo Kenneth Serbin, a modernização da sociedade (a urbanização e a difusão dos meios de comunicação de

\footnotetext{
${ }^{24}$ ROMANO, R. Brasil: Igreja contra Estado. São Paulo: Kairós, 1979. p. 153.

${ }^{25}$ Sobre a divisão entre esquerda e direita católica, cf.: MAINWARING, S. Igreja Católica e a política no Brasil. Rio de Janeiro: Brasiliense, 1989. p. 85-90; SERBIN, K. P. Padres, celibato e conflito social: uma história da Igreja Católica no Brasil. São Paulo: Companhia das Letras, 2008; MATA, S. R. da. "A dialética do aggiordamento". Revista do Arquivo Público Mineiro, n. 2, Belo Horizonte, jul./ dez. 2007, p. 147-158.
} 
massa) e o crescimento das igrejas protestantes (tradicionais e pentecostais) traziam dúvidas ao futuro do catolicismo. A modernização impulsionou uma crise de identidade do clero e dos leigos; buscavam novos meios de atuação, e a parte minoritária da Igreja optou por reforçar o "poder do laicato", a "luta pela justiça social" e os debates sobre a "realidade brasileira", contrapondo-se ao catolicismo tradicional. ${ }^{26}$

Em Belo Horizonte, os grupos ligados à Ação Católica e aos párocos de regiões operárias foram aqueles que empreenderam algumas inovações no catolicismo, mas eram minoritários na cidade. De acordo com Sérgio da Mata, a identidade católica conservadora era majoritária entre o clero e se articulava em uma rede de instituições do apostolado leigo (Congregados Marianos, Filhas de Maria, Apostolado da Oração, Movimento Familiar Cristão e Círculos Operários). Esses eram "inclinados a não se integrar, conviver ou assimilar elementos simbólicos provenientes de outras confissões e visões de mundo", seus representantes permaneceram fiéis ao breviário tridentino, defenderam o "assistencialismo no que diz respeito aos problemas sociais" e a "santa harmonia no que diz respeito às relações entre poder civil e eclesiástico". ${ }^{27}$

$\mathrm{O}$ associativismo de defesa coletiva era um movimento próximo à ala "progressista" do clero de Belo Horizonte, mas tinha também contato com "conservadores". No processo de renovação do catolicismo, havia ambiguidades nas posições políticas da ala que renovava as práticas religiosas da Igreja e dos leigos - em princípio, eles compartilhavam o éthos anticomunista e o ideal de defesa da ordem.

Todavia, na radicalização das posições politicas no Brasil e no papado de João XXIII (1958-1963), Padre Lage, leigos da Ação Católica e outros párocos na cidade aproximaram-se das mobilizações pelas reformas de base, influenciando o próprio movimento de favelas. Essa radicalização expressou-se na formação da Ação Popular (AP) a partir de uma divisão na

${ }^{26}$ SERBIN, K. P. Padres, celibato e conflito social: Uma história da Igreja Católica no Brasil. São Paulo: Companhia das Letras, 2008. p. 30-31.

${ }_{27}$ MATA, S. R. da. "A dialética do aggiordamento". Revista do Arquivo Público Mineiro, n. 2, Belo Horizonte, jul./dez., 2007, p. 149. 
Juventude Universitária Católica (JUC). Em Belo Horizonte, a AP contou com um "setor de favelas" que era composto por algumas lideranças do associativismo de favela. ${ }^{28}$

O viés conservador foi colocado como um matiz periférico do movimento de favelas no início da década de 1960. Em 1961, após Francisco Farias Nascimento e seu grupo assumirem a direção da FTFBH, houve uma guinada à esquerda, aumentando a relação das associações com as mobilizações pelas reformas de base. Empunhado por lideranças comunistas, trabalhistas, socialistas e católicas de esquerda, o nacionalismo ganhou corpo em mobilizações politicas e na vida associativa. Várias lideranças encarnaram as esperanças da comunidade na luta pela justiça social e pelo desenvolvimento autônomo da nação, radicalizando ações junto a outras associações civis e sindicatos para reivindicar as "reformas de base".

Durante o governo de João Goulart (1961-1964), a aproximação da FTFBH com as esquerdas nacionalistas foi o motivo para formação de divisões no movimento de favelas. Os grupos católicos conservadores, que antes conviveram dentro do movimento de favelas, passaram a se opor à direção da FTFBH. Imbuídos de um sentimento anticomunista, tencionavam manter as favelas ligadas a tradições cristãs, isoladas do "perigo vermelho".

\section{Organização Social dos Trabalhadores Favelados}

Em 1961, apareceu na Vila São Vicente de Paulo uma primeira manifestação clara de "divisão" do grupo ligado à Federação dos Trabalhadores Favelados. Na eleição para presidência da associação em novembro de 1961, a "Chapa da Renovação" 29 controlava a UDC da Vila São Vicente de Paulo e tentava a reeleição. O diretor e candidato à reeleição, Joaquim

\footnotetext{
${ }^{28}$ OLIVEIRA, S. S. R. de O. O movimento de favelas de Belo Horizonte. Rio de Janeiro: E-papers, 2010. p. 212-222.

${ }^{29}$ [Panfleto apresentando os componentes da "Chapa da Renovação", s/d] Arquivo Público Mineiro. Fundo DOPS. Pasta 0119.
} 
de Almeida Lopes, utilizou de seus contatos com a polícia para limitar as discussões nas assembleias e fechou a associação civil para evitar qualquer manifestação da oposição. ${ }^{30}$

A eleição de novembro de 1961 foi vencida pela situação, representada na "Chapa da Renovação"; a oposição integrada na "Chapa da Legalidade" acusou a falta de "liberdade de expressão" na associação e o "servilismo" de Joaquim de Almeida às autoridades públicas. Denunciou-se o comportamento do diretor Joaquim de Almeida, sublinhando a "inautenticidade" de sua liderança, "lutando mais ao lado do Prefeito" que dos favelados. $^{31}$

A UDC da Vila São Vicente de Paulo tinha um peso diferenciado no movimento social, ali se reconhecia o berço do associativismo de defesa coletiva. Por isso, tão logo surgiu uma oposição aos rumos esquerdistas assumidos pelo movimento, tentou-se isolar a tendência. A FTFBH não reconheceu a chapa eleita na UDC da Vila São Vicente, expulsando-a da Federação; ao mesmo tempo, reconheceu a associação "União Social Cristã" - onde se congregou a "Chapa da Legalidade", que tinha perdido a eleição "fraudada". Simultaneamente a essa manobra política, a Federação passou a atacar o enfraquecimento do "espírito de luta" da Vila São Vicente de Paula, que não reagiu às arbitrariedades cometidas pelo diretor da UDC. A edição do jornal $O$ Barraco sinalizou que os moradores daquela vila compartilhavam de um falso sentimento de "segurança"; haveria uma "falta de união" da Vila São Vicente, por ela estar se limitando a defender as melhorias de água, transporte e energia elétrica, sem se solidarizar com outras favelas. ${ }^{32}$

\footnotetext{
${ }^{30}$ Cf.: Última Hora, Belo Horizonte, 21 nov.1961, p. 5; [Relatório policial sobre denúncia de interferência de polícia na UDC da Vila São Vicente de Paula, 24 nov. 1961] Arquivo Público Mineiro. Fundo DOPS. Pasta 0119; [Relatório policial sobre reunião na UDC da Vila São Vicente, 20 abr.1961] Arquivo Público Mineiro. Fundo DOPS. Pasta 0119.

31 Cf.: [Panfleto "Ao povo da Vila São Vicente", 15 nov.1961] Arquivo Público Mineiro. Fundo DOPS. Pasta 0119; [Panfleto "Aos caros amigos da Vila São Vicente de Paula", 6 nov.1961]. Arquivo Público Mineiro. Fundo DOPS. Pasta 0119; Última Hora, Belo Horizonte, 21 nov.1961, p. 5.

32 [Vila São Vicente Ameaçada, O Barraco, jan.1962] Arquivo Público Mineiro. Fundo DOPS. Pasta 3239.
} 
A oposição à Federação iniciada na Vila São Vicente acentuou-se em 1962, com o maior envolvimento do movimento de favelas nas eleições municipais de 1962 e na campanha pela reforma urbana. Outras lideranças "inautênticas" foram expulsas e esse grupo de excluídos do movimento, pouco a pouco, começou a se unir. Passaram a visitar várias vilas, cooptando líderes de UDCs para fundação de um novo movimento, que não reconhecia nem a Federação, nem Francisco Nascimento como liderança dos "trabalhadores favelados". Esse movimento ganhava força, e recebia a atenção do jornal O Barraco: ${ }^{33}$

$\mathrm{Na}$ reunião do dia 2 de agosto, houve a leitura de uma carta de Vicente Gonçalves dirigida à Federação dos Trabalhadores Favelados, denunciando o movimento exótico de alguns elementos que foram banidos do nosso meio por serem traidores. Estes fariseus estão querendo em vão criar uma nova entidade com intenção de derrubar a nossa, tão bem orientada pelo companheiro Francisco Nascimento ${ }^{34}$.

Nas assembleias do movimento, chegou a haver embates entre os "divisionistas" e os lideres de esquerda das UDCs. $\mathrm{Na}$ visão da Federação, os dissidentes eram "alcaguetes da polícia", "servis" à prefeitura e parte da estratégia dos políticos e dos empresários imobiliários - "latifundiários do asfalto" para "roubar" os direitos dos moradores de favela. ${ }^{35}$

O movimento de oposição a Federação, inicialmente localizado na UDC da Vila São Vicente, culminou com a fundação da "Organização Social dos Trabalhadores Favelados", em 23 de janeiro de 1963, com sede na "Rua dos Tupinambás, 631, $3^{\circ}$ andar, sala 303". ${ }^{36}$ O presidente da entidade era Jorge da

\footnotetext{
${ }^{33}$ A partir de agosto de 1962, o jornal O Barraco foi publicado num espaço cedido pelo jornal Binômio, seguindo dessa forma até às vésperas do Golpe de 1964 . As notas de referência relativas ao periódico nesse período serão registradas da seguinte maneira: "Título da reportagem", O Barraco. In: Binômio, Belo Horizonte, data, página.

34 "Favelados denunciam que fariseus tentam divisão", O Barraco. In: Binômio, Belo Horizonte, 13 ago.1962, Caderno 3, p. 3.

35 "Divisionismo nas favelas volta a ser tentando: um dos autores foi da polícia", O Barraco. In: Binômio, Belo Horizonte, 20 ago.1962, Caderno 3, p. 3.
}

${ }^{36}$ Diário da Tarde, 2 fev.1963, p. 2. 
Costa Sady, que tinha sido expulso da FTFBH em 1962. Em termos de reivindicações, a nova entidade não se diferenciava da FTFBH: representava os "trabalhadores favelados" para garantir o direito de morar e para lutar por equipamentos urbanos. Todavia, almejavam o revigoramento de princípios de organização do movimento que estavam sendo esquecidos na voga esquerdista vivenciada pela FTFBH e pelas UDCs.

Para endossar princípios que garantiriam a ordem e a paz comunitária, declararam-se contrários a manifestações "político-partidárias", a "agitação ideológica", e a "demagogia”, colocando-se ao lado do governo e da Arquidiocese de Belo Horizonte para resolver os problemas dos moradores de favelas. Como ficou publicado na reportagem que anunciava a criação da associação:

Esta nova entidade dentro dos princípios cristãos, democráticos e humanos, deverá trabalhar para a melhoria das condições sociais dos favelados, sem falar em partidos, ideologias ou religião [...] Somos contra a agitação, contra a discórdia. Precisamos do apoio de todos, principalmente, da Associação Social Arquidiocesana, do Governo do Estado e do Prefeito da Capital $[\ldots]^{37}$

A Organização Social dos Trabalhadores Favelados fazia aliança com o poder público e com o aparato repressivo para afastar das favelas a ação dos esquerdistas. Ela almejava realizar conquistas por meio dos canais legais, evitando qualquer tipo de radicalismo e confronto com as autoridades. Por isso, se aproximou da polícia política, vendo nela uma aliada na luta contra a FTFBH. A carta enviada ao DOPS por uma associação, que se desligou da Federação e liderou a organização do movimento dissidente, era representativa da prática política assumida por esses atores:

III - Acontece que, infelizmente existe naquele bairro [Vila São Vicente de Paulo], um núcleo ativo de comunistas que não vê com bons olhos a atuação da associação e principalmente o seu programa de resolver o problema do favelado, sem violência, legalmente e obedecendo os poderes constituídos.

${ }^{37}$ Diário da Tarde, Belo Horizonte, 2 fev.1963, p. 2. 
IV - Em vista disso fundaram eles, agora pouco, uma entidade denominada "Associação Cristã", que outro intuito não tem tido, senão pregar a violência, a discórdia, a cizânia, o desrespeito às autoridades e outras coisas mais [...]

Em vista do exposto, requerem a V. Excia., a abertura de rigoroso inquérito e que sejam os culpados punidos de acordo com as Leis Penais e a Segurança Nacional $[\ldots]^{38}$

Apesar da institucionalização, a nova entidade não conseguiu disseminar-se e captar indivíduos contrários à Federação. O reconhecimento público e a confiança adquirida pela FTFBH superavam a articulação do "novo" movimento. Havia pessoas contrárias à esquerdização do movimento, mas elas conviviam com essa tendência sem grandes conflitos, desde que suas demandas fossem atendidas. Exemplo disso é a trajetória de Manoel Ferreira, da Vila Santa Lúcia: sendo vice-presidente da UDC, era contra os "comunistas" e toda a agitação promovida por "Brizola", tendo aconselhado os moradores a não participar das campanhas reformistas. ${ }^{39}$ Nem por ter essas posições ele deixou de participar e ajudar a associação de sua favela, pois através dela conseguia alguns beneficios que, possivelmente, a Organização Social dos Trabalhadores não estava apta a oferecer.

Apesar de existir a intenção de reunir forças para formar um movimento social em bases dissidentes, contrários à esquerdização da luta dos favelados, tudo indica que os embates e conflitos foram localizados e fragmentários. O exemplo mais contundente disso aconteceu na favela Operário-Estudantil, constituída a partir da invasão/ocupação dos terrenos de Antonio Luciano, ${ }^{40}$ na segunda metade de 1963. Ali surgiu um

\footnotetext{
${ }^{38}$ [Carta da Associação de Defesa Coletiva da Vila São Vicente de Paula ao DOPS, 8 jan.1963] Arquivo Público Mineiro. Fundo DOPS. Pasta 0119.

${ }^{39}$ SANTOS, M. F. Belo Horizonte, Brasil, 16 fev. 2007, Arquivo WAVE (103 min.), Entrevista concedida ao pesquisador.

${ }^{40}$ Antônio Luciano Pereira Filho é conhecido por atividades bancárias e imobiliárias, adquiriu grande porção de lotes em Belo Horizonte ao longo do século XX. Foi declarado como inimigo "número um" do movimento de favelas, sendo seus terrenos ocupados em sinal de protesto político pela reforma urbana.
} 
forte movimento contrário à UDC local, mas não foi canalizado pela Organização Social dos Trabalhadores Favelados.

\section{A oposição organizada por Isabel Bastos}

Entre final de 1963 e início de 1964, estruturou-se na Vila Operário-Estudantil, próximo à favela Cabana do Pai Tomás, um movimento opositor com características semelhantes à Organização Social dos Trabalhadores Favelados. Seu principal objetivo era evitar a esquerdização da luta social naquela favela, para preservar o caráter cristão da comunidade, em prol da "democracia e dos necessitados". O movimento liderado por Isabel Bastos contava com a participação dos Congregados Marianos. Não há dados sobre quando e quem fundou a Congregação Mariana da Vila Operário-Estudantil, mas a associação reunia o apostolado leigo na adoração à Virgem Maria e fazia ações de caridade e assistência social. No Brasil, essas associações foram introduzidas pelos jesuitas e se reuniam em torno de uma Confederação Nacional, fundada em 1937.

O movimento liderado por Isabel Bastos tinha franca colaboração compartilhava o ethos anticomunista e o mito de que as favelas estavam sendo "cubanizadas". Como ficava registrado na primeira reunião do movimento:

[...] da finalidade desta reunião é que já não é mais possível continuarmos na Favela sob jugo do ditador vermelho Raimundo Gil, pelas suas perseguições aos moradores que não dão dinheiro para ele, pelas explorações vendendo terrenos que não são dele [...]

Diz ainda a senhora Isabel que somos um povo noventa e oito por cento cristão e não ser possivel concordarmos com a ideologia comunista de Raimundo Gil, que inclusive vem ameaçando a igreja de depredações na vã tentativa de transformar a Cabana em um satélite de Cuba ou da URSS. ${ }^{41}$

Esse grupo não tencionava construir as bases de um novo movimento para substituir a FTFBH, como foi o

$\overline{41}$ [Ata de reunião da oposição a Raimundo Gil, 17 mar.1964] Arquivo Público Mineiro. Fundo DOPS. Pasta 0240. 
objetivo da Organização Social dos Trabalhadores Favelados; o combate era específico contra Raimundo Gil, presidente da UDC local. Havia dúvidas quanto ao real apoio da FTFBH à UDC da Vila Operário-Estudantil. Compreendiam que o diretor da UDC trabalhava contra Francisco Nascimento e pretendia tomar-lhe a direção do movimento social. Numa das reuniões do grupo, sugeriu-se buscar ajuda da Federação para barrar o crescimento da associação da favela e do poder do presidente da entidade, que utilizava de sua posição para explorar os moradores locais, vendendo lotes. Apesar disso, outros compreendiam que toda a Federação era comunista, sendo inútil pedir apoio dessa entidade. ${ }^{42}$

O coletivo liderado por Isabel Bastos requeria o direito de ter uma vida religiosa despolitizada na favela. O presidente da UDC era filiado ao Partido Comunista Brasileiro e sua esposa, Maria da Conceição Moura, era sócia da Liga Feminina; ${ }^{43}$ eles tinham leituras diferentes sobre o lugar da religião na vida comunitária. O presidente da UDC chamava Padre Ozanan para celebrar missas - ele era um padre "progressista" que militava na campanha pela reforma urbana. O uso do espaço da casa de Raimundo Gil para o culto e ausência de pompa religiosa, sendo os sacramentos feitos sem "água benta" e com uma "cruz de pau", causavam revolta entre os Congregados Marianos, que, por sua vez, entendiam que a vida religiosa da comunidade era desvirtuada por um "ditador vermelho". ${ }^{44}$

As lideranças da UDC mantiveram uma relação de competição com os conservadores católicos, impedindo sua atuação na favela. Os congregados marianos buscavam apoio do petebista Waldomiro Lobo, argumentando que estavam sendo impedidos de distribuir "alimentos", "roupas e outros utensilios aos pobres"; Raimundo Gil e seu grupo faziam campanha na favela alegando que os produtos estavam "contaminados pelos

\footnotetext{
${ }^{42}$ Ibidem.

${ }^{43}$ Movimento vinculado ao Partido Comunista Brasileiro, liderado em Minas Gerais por Adamastora Andreazi.

44 [Ata de reunião da oposição a Raimundo Gil, 17 mar.1964] Arquivo Público Mineiro. Fundo DOPS. Pasta 0240.
} 
germes de tuberculose". ${ }^{45} \mathrm{O}$ mesmo teria acontecido com os alimentos enviados pelo governador Magalhães Pinto ${ }^{46}$ através de sua esposa, Berenice Cantão; o líder favelado utilizou o alto falante da UDC para incitar os favelados a não receberem os mantimentos, por serem "restos da Aliança para o Progresso", denunciando que o governo de Minas trocava "feijão por minério". ${ }^{47}$ Isabel Bastos foi também impedida de dar aulas para as crianças pobres, sob ameaça de Raimundo Gil e sua esposa. $^{48}$

A estratégia dos conservadores para derrotar Raimundo Gil foi fazer uma forte aliança com a Polícia Militar (PM). A ajuda à PM era assumida de forma clara, existindo orgulho em serem colaboradores. Numa reunião do grupo de Isabel Bastos, esse apoio foi criticado por Padre Ozanan, que tentava conclamar a "união" dos moradores para resistirem ao possivel despejo a ser feito pelos policiais. Contrapondo-se a essa fala, um dos integrantes da oposição à UDC contra-argumentou: "estavam ligados à polícia porque sem esta não poderia haver ordem e respeito, e quanto a se unir a UDC era praticamente impossivel. Porque dentro da Federação da UDC só não é comunista o quadro negro e os demais móveis". ${ }^{49}$

Isabel Bastos, a líder do grupo de oposição à UDC, escreveu um diário que seria entregue a polícia para ser usado como prova das arbitrariedades cometidas por Raimundo Gil e sua esposa. ${ }^{50}$ Num primeiro momento, ela se infiltrou na Liga Feminina coordenada pela esposa de Raimundo Gil, frequentando reuniões e anotando no diário tudo que

\footnotetext{
45 [Carta de Maria Isabel Bastos a Waldomiro Lobo, 31 mar.1964] Arquivo Público Mineiro. Fundo DOPS. Pasta 0240; [Diário de Isabel Bastos, 1964] Arquivo Público Mineiro. Fundo DOPS. Pasta 0121.

${ }^{46}$ Liderança da União Democrática Nacional (UDN) em Minas Gerais, governando o estado entre 1961 e 1965.

${ }_{47}$ [Relatório policial da PM sobre atividades políticas na Cabana do Pai Tomás, 7 fev.1963] Arquivo Público Mineiro. Fundo DOPS. Pasta 0119.

48 [Diário de Isabel Bastos, 1964] Arquivo Público Mineiro. Fundo DOPS. Pasta 0121.

49 [Ata de reunião da oposição a Raimundo Gil, 17 mar.1964] Arquivo Público Mineiro. Fundo DOPS. Pasta 0240.

${ }^{50}$ Ibidem.
} 
acontecia. Depois, quando entrou em confronto com a diretora da Liga, foi expulsa e passou a observar as ações de Raimundo Gil na direção da UDC. Através dessas investigações, chegou à conclusão de que Raimundo Gil encontrava-se com estrangeiros, possiveis oficiais do exército cubano em excursão na cidade, e contratava um pistoleiro para matar os PMs que cuidavam da segurança do local. ${ }^{51}$ A líder do grupo foi à imprensa relatar suas descobertas, como noticiou o jornal Estado de Minas:

Uma jovem que ainda não pode ter o seu nome divulgado, ouviu uma conversa entre Raimundo Gil da Silva e um elemento estranho à favela, nas proximidades do "Cabana Clube", situado na Avenida Amazonas. O líder comunista teria proposto ao visitante a contratação de um pistoleiro em Governador Valadares, para eliminar os militares. ${ }^{52}$

$\mathrm{Na}$ imprensa, as declarações de Isabel Bastos tiveram repercussão e serviram para incriminar o movimento de favelas. Os alvos do "plano de morte" de Raimundo Gil seriam os responsáveis pelo destacamento policial na Cabana do Pai Tomás, capitão Eustáquio Murilo, sargento Geraldo Alves e o soldado Napoleão Braga Barroso. Outro marcado para ser assassinado era o cabo Antonio Afonso (que apreendeu armas em mãos dos acompanhantes do deputado Leonel Brizola na visita que faria a Belo Horizonte, no início de 1964). Na visão de Isabel Bastos, Brizola era a liderança de uma conspiração comunista no Brasil; em vista disso, sempre procurou reportar em seu diário as ligações e referências das lideranças locais com o líder trabalhista. ${ }^{53}$

O diário de Isabel Bastos foi peça importante para a polícia: era a comprovação das acusações lançadas na imprensa e constituiu prova de acusação do inquérito policial instaurado pelo DOPS. Mostrava a colaboração de parte dos moradores de favelas com a polícia e a legitimação das ações repressivas desencadeadas pelo aparato repressivo no golpe civil e militar.

${ }_{51}$ [Diário de Isabel Bastos, 1964] Arquivo Público Mineiro. Fundo DOPS. Pasta 0121.

${ }^{52}$ Diário da Tarde, Belo Horizonte, 2 mar. 1964, p. 10.

${ }^{53}$ [Diário de Isabel Bastos, 1964] Arquivo Público Mineiro. Fundo DOPS. Pasta 0121. 


\section{Considerações finais}

A "onda anticomunista" que antecedeu o Golpe de 1964 contou com o apoio de moradores de favelas, existindo engajamento no apoio ao aparato repressivo de Estado para combater organizações de esquerdas percebidas como entidades "subversivas". O movimento social organizado em torno da Federação dos Trabalhadores Favelados de Belo Horizonte foi alvo de tal ataque. $\mathrm{O}$ inquérito policial para apurar atividades políticas nas favelas e a intervenção na FTFBH movida pelo Coronel Gradinor Soares, após o Golpe, receberam apoio e legitimidade dessa mobilização de direita nas favelas.

$\mathrm{O}$ associativismo difundido nas favelas pela FTFBH compartilhava de um éthos comunitário, com raizes na renovação da doutrina social da Igreja Católica após a Segunda Guerra Mundial. Leituras "progressistas", abertas ao diálogo com outras correntes politicas, e "conservadoras", fechadas ao diálogo, foram em princípio compatibilizadas no interior do movimento de favelas. No início da década de 1960, a aproximação com as esquerdas e com a luta pelas reformas das estruturas sociais brasileiras desencadeou o confronto entre católicos conservadores e a FTFBH.

Nessa perspectiva, localizamos dois movimentos opositores à FTFBH: a Organização Social dos Trabalhadores Favelados e o movimento liderado por Isabel Bastos, na Vila Operário-Estudantil. A primeira tentou articular uma mobilização em larga escala, ligando várias favelas para refundar o movimento social em princípios "cristãos, democráticos e humanos". O segundo restringiu-se a uma favela, não mostrando o grande empenho propagandista contra a FTFBH. Preocupou-se mais com a ação do presidente da UDC local e as restrições que ele impunha às atividades religiosas e assistencialistas na Vila Operário-Estudantil.

Esses conflitos apresentam a força das representações e da cultura como meio de mobilizar os atores coletivos. Ainda que tivessem objetivos materiais coincidentes - ampliar a assistência social e os direitos dos moradores, tinham identidades politicas distintas e rivalizaram a luta pela organização 
das práticas organizativas do associativismo civil em favelas. Estava em jogo uma luta pela representação do mundo social, que delimitava as identidades e a legitimidade dos grupos politicos.

Resumo: O artigo analisa o movimento de favelas organizado pela Federação dos Trabalhadores Favelados de Belo Horizonte e sua relação com o conservadorismo católico. O enfoque é a influencia da cultura católica no movimento social e a constituição das dissidências a partir da formação Organização Social dos Trabalhadores Favelados e da oposição na Vila Operário-Estudantil. O artigo é uma contribuição à renovação dos estudos sobre a direita no período anterior ao Golpe de 1964, sob influência da história cultural.

Palavras-chave: Favela. Cultura política católica. Golpe de 1964.

Abstract: The present article analyses the social movement in the favelas in the city of Belo Horizonte, organized by the Federação dos Trabalhadores Favelados de Belo Horizonte, and its relationship with the conservative Catholics. The main focus of the research is the catholic political culture regarding the social movement, the dissent in the movement after the establishing of the Organização Social dos Trabalhadores Favelados, and the opposition to it in the Vila OperárioEstudantil. This work aims at contributing to the renewal of the studies on right-wing politics in Brazil prior to the Military Coup of 1964, under the influence of the cultural history approach.

Keywords: Favela. Catholic political culture. Military Coup of 1964.

Artigo recebido para publicação em 04/10/2010.

Artigo aceito para publicação em 18/11/2011. 